\title{
Sucrose consumption and salivary sucrase activity in a 2-year longitudinal study
}

\author{
S. KARJALAINEN', P. HANNULA', E. SÖDERLING', M. HÄMÄLÄINEN' ${ }^{1}$, K. MÄKINEN² \\ AND A. SGHEININ' \\ ${ }^{1}$ Institute of Dentistry, University of Turku, Turku, Finland; ${ }^{2}$ School of Dentistry, University of Michigan, \\ Ann Arbor, Michigan, USA
}

\begin{abstract}
Karjalainen S, Hannula $P$, Söderling E, Hämäläinen M, Mäkinen K, Scheinin A: Sucrose consumption and salivary sucrase activity in a 2-year longitudinal study. Scand J Dent Res 1989; 97: 401-4.

Abstract - Sucrose consumption data of the sucrose group $(n=33)$ of a 2-yr longitudinal study was plotted against salivary sucrase activity values obtained during this 2 -yr period. The correlation coefficients varied between 0.194 and 0.551 . The subjects were divided into high $\left(\geq 10 \mu \mathrm{mol} \times \min ^{-1} \times\left(10^{-3}\right)\right)$ and low $(<10)$ sucrase activity subgroups. There were significant differences in the sucrose consumption and in intake frequency between these two subgroups. These findings give further support for the possibility of using sucrase activity for the estimation of the level of individual sugar consumption.
\end{abstract}

Key words: dietary carbohydrates; microbial enzymes; salivary test.

S. Karjalainen, Institute of Dentistry, University of Turku, SF-20520 Turku, Finland.

Accepted for publication 11 February 1989.

In a recent study we observed that strict restriction of dietary sucrose over a 2-wk period effectively reduced high salivary sucrase, i.e invertase-like activity (1). We have now examined whether less profound alterations in sucrose consumption can be detected through sucrase activity of whole saliva and whether there is a relationship between sucrose consumption, frequency of intake and salivary sucrase activity. For these purposes the sucrose consumption and the salivary sucrase activity values of the sucrose group subjects of the Turku sugar studies 12 , 3) were reanalyzed.
In the Turku studies, the sucrose group $(n=33)$ comprised 13 men and 20 women, aged $27.2 \mathrm{yr}$ in average. The salivary sucrase. activity was determined six times during the $2-y$ r study at 4-6-month intervals as described in Table 1. The supernatant fluid of centrifuged $\left(12000 \mathrm{~g}, 10 \mathrm{~min}\right.$ at $\left.4^{\circ} \mathrm{C}\right)$ paraffin wax-stimulated whole saliva was used for the sucrase assay $(3-5)$.

The subjects recorded their sucrose consumption daily over the entire 2-yr study using a specially designed dietary diary (2). A total of 24-monthly sucrose consumption values were thus calculated. Out of these 
values, those five which preceded each sucrase activity determination during the 2-yr study, were used in the present context. The baseline sucrase activity values were excluded as there was no previous dietary history.

The comparison between sucrase activity and sucrose consumption (Table 1) showed that the nonlinear, Spearman correlation coefficient values $(R)$ varied between 0.194 and 0.419 . When the extreme sucrase values, i.e. values over $50 \mu \mathrm{mol} \mathrm{min} \mathrm{mg}^{-1} \mathrm{mg}^{-1}\left(\times 10^{-3}\right)$ were excluded, the linear coefficient values (R) ranged between 0.222 and 0.551 (Taßle 1). The average sucrose consumption showed a decreasing trend during the course of the study (Tables 1 and 2). The high values during the early phases of the study were thought to be due to the availability of sucrose-containing products free of charge during the entire study period. Presumably the subjects reverted from increased use to their earlier sucrose consumption habits. The coefficient values between salivary sucrase activity and sucrose consumption shown in Table 1 were higher than those between salivary lactobacillus counts and sucrose intake reported recently by STECKsÉN-BLICKs (6) in chilldren.

The subjects whose data were available $(n=32)$ were divilded in to two subgroups according to the sucrase activity values. The values $\geq 10 \mu \mathrm{mol} \mathrm{min}{ }^{-1}$ and $\mathrm{mg}^{-1}\left(\times 10^{-3}\right)$ were considered high $(n=14 ; \bar{x}=26.2, \mathrm{SD}$ 22.5 , while the values below this level were considered low or moderate $(n=18 ; \bar{x}=4.7$, SD 1.9). Between these two subgroups there were significant differences in the sucrose consumption $(\bar{x}=63.3$, SD 26 . I vs $\bar{x}=44.2$, $\mathrm{SD} 18.6 \mathrm{~kg} / 2 \mathrm{yr} ; P<0.02)$, in the sucrose intake frequency $(\bar{x}=5.6, \mathrm{SD} 1.5$ vs $\bar{x}=4.1$, SD 1.5 times/day; $P<0.01$ ) and in the sucrase activity $(P<0.001)$.

Earlier (1) it has been suggested that sucrase activity could be used as a diagnostic test to reveal the level of individual sucrose consumption. Therefore the ability of the present sucrase activity values to identify individuals using excessive amounts of sucrose from those who use moderate or scarce amounts was tested. The ability of a sucrase activity measurement (sucrase test) to identify subjects who used more (high-scale consumers) or less (low-scale consumers) sucrose than on the average ( $2.2 \mathrm{~kg} /$ month) is shown in Table 2. The probability of a high sucrase activity (positive sucrase test) among highscalle consumers (sensitivity) varied between 0.38 and 0.65 , while the probability of a low sucrase activity (negative sucrase test) among low-scale consumers (specificity) varied between 0.69 and 0.86 . The proportion of correct estimation of sucrose consumption obtained by the sucrase test (accuracy) var-

Table 1

Pairwise coefficients of correlation (Spearman, $R$ ) at five determinations of salivary sucrase activity and sucrose consumption (kgimonth). The values are meanis $\pm S D(\mathrm{n}=39)$

\begin{tabular}{|c|c|c|c|c|c|c|}
\hline \multirow[b]{2}{*}{ Date } & \multicolumn{2}{|c|}{$\begin{array}{l}\text { Sucrase } \\
\text { activity }\end{array}$} & \multicolumn{2}{|c|}{$\begin{array}{c}\text { Sucrose } \\
\text { consumption }\end{array}$} & \multicolumn{2}{|c|}{$\begin{array}{c}\text { Correlation } \\
\text { coefficient }\end{array}$} \\
\hline & Mean & (SD) & Mean & (SD) & $\mathrm{R}$ & $\left(\mathbb{R}^{\prime}\right)$ \\
\hline Jan 1973 & 16.5 & $(22.0)$ & 2.6 & $(1.3)$ & 0.419 & $(0.386)$ \\
\hline May 1973 & 19.7 & $(32.9)$ & 2.5 & (1.3) & 0.261 & $(0.222)$ \\
\hline Oct 1973 & $11: 3$ & $(14.9)$ & 2.2 & (1.2) & 0.194 & $(0.372)$ \\
\hline May 1974 & $11: 8$ & $(17,1)$ & 1.8 & $(1.2)$ & 0.330 & $(0.551)$ \\
\hline Oct 1974 & 13.4 & $(21.3)$ & 1.7 & (1.1) & 0.362 & $(0.411)$ \\
\hline
\end{tabular}

$\mathrm{R}^{\prime}$ correspond to coefficients of linear correlation calculated after excluding the extreme sucrase activity values $\geq 50 \mu \mathrm{mol} \mathrm{min}-1 \mathrm{mg}^{-1}\left(\times 10^{-3}\right)$. 
Table 2

Distribution of subjects into two sucrose consumption and two sucrase activity* categories at five determinations carried out during the 2-yr longitudinal study. The ability of the sucrase test to idenify individials consuming more or teis sucrose (kg/mo) than on the average is indicated in terms of sensativity ( $S n)$, specificity (Sp), accuracy (A), positive $(P p o)$, and negatioe predictive values ( $N p v)$

\begin{tabular}{|c|c|c|c|c|c|c|c|c|c|}
\hline \multirow{2}{*}{$\frac{\text { Date }}{\text { Jan } 1973}$} & \multirow[t]{2}{*}{$\begin{array}{l}\text { Sucrase } \\
\text { activity }\end{array}$} & \multicolumn{2}{|c|}{$\begin{array}{c}\text { Sucrose } \\
\text { consumption }\end{array}$} & & \multirow[t]{2}{*}{$\mathrm{Sn}$} & \multirow[t]{2}{*}{$\mathrm{Sp}_{\mathrm{p}}$} & \multirow[t]{2}{*}{ A } & \multirow[t]{2}{*}{$\mathbb{P p v}$} & \multirow[t]{2}{*}{ Npv } \\
\hline & & $>2.2$ & $\leq 2.2$ & & & & & & \\
\hline & $\geq 10.0$ & 13 & 4 & 17 & 0.65 & 0.69 & 0.67 & 0.76 & 0.56 \\
\hline & $<10.0$ & 7 & 9 & 16 & & & & & \\
\hline & & 20 & 13 & & & & & & \\
\hline \multirow[t]{4}{*}{ May 1973} & & $>2.2$ & $\leq 2.2$ & & & & & & \\
\hline & $\geq 10.0$ & 7 & 5 & 12 & 0.44 & 0.71 & 0.58 & 0.58 & 0.57 \\
\hline & $<10.0$ & 9 & 12 & 21 & & & & & \\
\hline & & 16 & 17 & & & & & & \\
\hline \multirow[t]{4}{*}{ Oct 1973} & & $>2.2$ & $\leq 2.2$ & & & & & & \\
\hline & $\geq 10.0$ & 5 & 5 & 10 & 0.38 & 0.75 & 0.61 & 0.50 & 0.65 \\
\hline & $<10.0$ & 8 & 15 & 23 & & & & & \\
\hline & & 13 & 20 & & & & & & \\
\hline \multirow[t]{4}{*}{ May 1974} & & $>2.2$ & $\leq 2.2$ & & & & & & \\
\hline & $\geq 10.0$ & 5 & 3 & 8 & 0.45 & 0.86 & 0.73 & 0.63 & 0.76 \\
\hline & $<10.0$ & 6 & 19 & 25 & & & & & \\
\hline & & 11 & 22 & & & & & & \\
\hline \multirow[t]{4}{*}{ Oct 1974} & & $>2.2$ & $\leq 2.2$ & & & & & & \\
\hline & $\geq 10.0$ & 4 & 6 & 10 & 0.44 & 0.75 & 0.67 & 0.40 & 0.78 \\
\hline & $<10.0$ & 5 & 18 & 23 & & & & & \\
\hline & & 9 & 24 & & & & & & \\
\hline
\end{tabular}

* Sucrase activity is expressed as $\mu \mathrm{mol} \mathrm{min}^{-1} \mathrm{mg}^{-1}\left(\times 10^{-3}\right)$.

ied between 0.58 and 0.73 . The prevalence of high-scale consumers decreased from $61 \%$ to $27 \%$ during the study (Table 2). The predictive value of a positive sucrase test decreased from 0.76 to 0.40 while that of a negative test increased from 0.56 to 0.78 (Table 2).

Thus, the determination of salivary sucrase activity reflected the amount, variation, and intake frequency of sucrose consumption at a group level. The correlation between sucrose consumption and sucrase activity was relatively high at the beginning of the study when the majority of the subjects used more sucrose than on the average, and again after 24 months when the proportion of high-consumers was considerably reduced. However, changes in individual sucrose consumption were not always detectable in the sucrase activities.

\section{References}

1. Karjalainen S, Hämäläinen M, KarhuvaAra $L$, SöderLing E. Effect of variations in sucrose consumption on salivary lactobacillus 
count and sucrase activity in man. Acta Odontol Scand 198\%; 45: $289-96$.

2. MAKINEN KK, ScheInin A. Turkw sugar studies. VI. The administration of the trial and the control of the dietary regimen. Acta Odontol Scand 1975; 33: Suppl. 70, 105-27.

3. MäkInen KK, Sahernin A. Turku sugar studies. VII. Principal biochemical findings on whole saliva and plaque. Acka Odontol Scand $1975 ; 33$ : Suppl. 70, 129-71.

4. Hostetter F, Borel. E, Deuel H. Über die
Reduktion der 3.5y-dizütrosalicylsäure durch Zucker. Helv Chim Acta 1951; 34: $2132-9$.

5. Saremin A, MÄINEN KK. The effect of various sugars on the formation and chemical composition of dental plaque. Int Dent 71971 ; 21: $302-21$.

6. Stécksén-BLicks C. Lactobacilli and Streptococcus mutans in saliva, diet and caries increment in 8-and 13-year-old children. Soand 7 Dent Res 1987; 95: 18-26. 
This document is a scanned copy of a printed document. No warranty is given about the accuracy of the copy. Users should refer to the original published version of the material. 